\title{
Políticas regionales en Argentina. Tensiones entre el Estado, la gobernanza y el espacio regional ${ }^{1}$
}

\author{
José Vigil \\ Universidad Nacional del Litoral - Argentina \\ Waldemar Ockstat \\ Universidad Nacional del Litoral - Argentina
}

\section{Resumen}

El trabajo es una intervención en el debate actual analítico y práctico sobre las características de las políticas de desarrollo económico regional y las dinámicas de gobernanza con un análisis exploratorio en Argentina (Santa Fe) durante 2001-2015. En el marco de un Estado transformado (descentralización de funciones, re jerarquización de las regiones, y apogeo de la gobernanza) el trabajo sugiere que ha habido una exagerada fe en las redes de gobernanza para implementar políticas regionales y que eso ha sido problemático para la efectividad de esas políticas. Propone una discusión en torno a tres hipótesis articuladas: i) que ha existido poco apoyo concreto por parte del Estado a esas dinámicas de gobernanza, ii) que ha existido una inadecuada relación entre los niveles de regulación (nacional, regional, local) para aplicar políticas basadas en dinámicas de gobernanza; y iii) que existe un gap muy grande entre las ideas políticas sobre el espacio regional de la gobernanza y la concreción de las políticas en el espacio regional. La investigación apunta a repensar hacia futuro las políticas de regeneración económica regional desde el Estado regional.

Palabras claves: Gobernanza. Políticas Regionales. Estado. Santa Fe. Regiones.

${ }^{1}$ Los autores agradecen las oportunas observaciones realizadas durante el proceso de evaluación anónimo del artículo. 


\title{
Regional policies in Argentina. Feeling of tension among the State, the governance and the regional space.
}

\begin{abstract}
This work is an intervention on the recent theoretical and empirical debate about the characteristics of the regional economic development policies and its governance dynamics, with an exploratory analysis on Argentina (Santa Fe) during 2001-2015. In the context of a transformed Argentinian state (devolution, rescaling regions, and rise of governance), this work suggest that there has been an exaggerated faith on the governance networks capacity to implement regional policies, and that it has been problematic for the effectiveness of those policies. It suggest a debate around three articulated hypothesis: i) that there has been little or no support from the State to the governance networks; ii) that there has been an inadequate relation among the different levels of regulation (national, regional, local); iii) that there has been a big gap between the policies ideas about the regional space of governance and the existing space of governance where policies implement. The research aim to rethink, from within the regional State, the regional economic regeneration policies.
\end{abstract}

Keywords: Governance. Regional policies. State. Santa Fe. Regions.

\section{Políticas regionais na Argentina. Tensões entre o Estado, a governança e o espaço regional}

\section{Resumo}

Este trabalho é uma intervenção no recente debate teórico e empírico sobre as características das políticas de desenvolvimento econômico regional e sua dinâmica de governança com uma análise exploratória sobre a Argentina (Santa Fé) no período 20012015. No contexto de um Estado transformado (descentralização de funções, reescalonamento de regiões e ascensão da governança), este trabalho sugere que há uma crença exagerada sobre a capacidade das redes de governança para implementar políticas regionais, e que tem sido problemática para a efetividade dessas políticas. Propõe uma discussão em torno de três hipóteses: i) de que houve pouco apoio concreto por parte do Estado a essas dinâmicas de governaça, ii) que houve uma relação inadequada entre os níveis de regulação (nacional, regional e local) para aplicar políticas baseadas na dinâmica de governança; e iii) que existe uma grande lacuna entre ideias políticas sobre o espaço regional de governança e a concretização de políticas nesse espaço regional. a pesquisa tem como objetivo repensar a partir do interior do estado, as políticas regionais de regeneração econômica.

Palavras-chave: Governança. Políticas Regionais. Estado. Santa Fe. Regiões.

\section{Introducción}

El trabajo es una intervención en el debate conceptual y empírico sobre las características de las políticas de desarrollo económico regional en Argentina durante la etapa que los economistas suelen llamar como nuevo desarrollismo (20012015). Durante este período, Argentina experimentó un fuerte rol planificador de su Estado nacional, con un gran impulso descentralizador, industrializador, regionalista y de fomento a las articulaciones público-privadas. Sostendremos sin embargo, que existió una constante tensión entre ese intento de planificación, el despliegue de las políticas de desarrollo económico regional, y las dinámicas de gobernanza. Más 
específicamente, existió una exagerada fe en las redes de gobernanza para implementar políticas regionales y que eso ha sido problemático para la efectividad de esas políticas.

En ese contexto, por un lado, se analizan algunas de las principales transformaciones ocurridas sobre el Estado en los últimos años en Argentina que iban en la dirección de colocarlo como un actor descentralizado y ameno a potenciar dinámicas de gobernanza. Por otro lado, y desde un nivel más empíricopráctico, se describe un estudio exploratorio sobre algunas tensiones y dificultades ocurridas en la aplicación de políticas regionalistas fruto de esas transformaciones en el Estado para el caso de una de las provincias más importantes de Argentina: Santa Fe. Se argumenta que estas transformaciones sobre el Estado, en parte con un gran acierto conceptual, han empujado las políticas regionalistas hacia una dinámica de articulaciones entre Estado y sociedad civil que no ha sido necesariamente favorable a su efectividad; contrariando paradojalmente la intención inicial de lograr una mejora de políticas por descentralización y articulación públicoprivada. Tres aspectos son explorados a ese nivel regional. La participación del Estado en las dinámicas de gobernanza, las articulaciones entre los diferentes niveles de articulación (nacional, regional, local) para ejecutar políticas regionales; los resultados efectivos de las políticas regionalistas.

La propuesta del trabajo no es solo crítica, por el contrario. Reconociendo ciertas virtudes en el espíritu planificador del Estado nacional hacia las políticas regionalistas el trabajo revisa algunas debilidades sobre las interacciones y dinámicas macro contextuales de la política económica y micro experimentales de una región en la articulación entre Estado, gobernanza y espacio regional para repensar hacia futuro las políticas de regeneración económica regional en Argentina.

El trabajo se estructura de la siguiente manera: la segunda sección analiza la transformación del Estado hacia la gobernanza en el desarrollo regional para el caso argentino. La tercera sección analiza ese giro para el caso de Santa Fe. La cuarta sección describe y analiza las dificultades y problemas empírico-prácticos que ese giro hacia la gobernanza ha tenido en la provincia de Santa Fe. La quinta sección a modo de conclusión ensaya algunas ideas para repensar la política regional.

\section{El giro teórico-político del Estado hacia la gobernanza regional y el surgimiento de las políticas de regeneración económica en Argentina}

Un buen punto de partida para describir los problemas de las políticas de regeneración económica regional en Argentina puede ser la descripción de la manera en que se dieron esas transformaciones del Estado hacia la gobernanza como pretexto para mejorar la eficacia de las políticas regionalistas.

Lentamente, en los últimos 30 años, el debate académico y político del desarrollo económico de ciudades, regiones y sistemas urbanos fue reconociendo que en la definición y aplicación de políticas y/o programas, y la prestación de servicios, predominaban esquemas poli-céntricos dinamizados por una pluralidad de actores en supuesta igualdad de condiciones de diálogo localizados a diferentes niveles institucionales que generaban acuerdos innovadores aparentemente 
democráticos que daban soluciones prácticas a situaciones que anteriormente eran en su mayoría provistas por el Estado (nacional, provincial y local). Ya desde fines de los 705 y principios de los 80s, en el marco de un intenso proceso de transformaciones tanto en las formas de producción keynesiano-fordistas como en la morfología de intervención del Estado (sobre todo nacional) en las economías capitalistas fue ganando lugar incipientemente el concepto de gobernanza para definir esos esquemas poli-céntricos, permitiendo reanimar los espacios de intervención del Estado tendiente a hacer la actividad de gobierno más reflexiva, participativa y democrática en su interacción con la sociedad civil. Los debates de la literatura especializada indicaban que dichos esquemas parecían más efectivos en la realización de la política y la prestación de servicios comparada con la esclerótica, jerárquica y en ocasiones autoritaria forma estatal (Hajer \& Wagenaar, 2003; Healey, 2006) $)^{2}$. Entrados los 90s, los nombres y esquemas vinculados a la gobernanza emergieron con mayor nitidez, se consolidaron en los enfoques del desarrollo (y del desarrollo regional) y justificaron (y demandaron) el surgimiento de mayores estructuras descentralizadas.

No pocos estudios comenzaron a relacionar Gobernanza con Desarrollo a partir de analizar los indicadores económicos de los países tanto en estudios macro comparados (comparar Kaufman \& Kraay, 2002; WorldBank, 2000) como con estudios de caso específicos por países. A veces se utilizó la idea de gobernanza en sentido amplio incluyendo no solo las modificaciones hacia las formas de gestión articulada y reflexiva de la política pública sino también los análisis vinculados a lo que cierta parte de la literatura fue denominando "buena gobernanza", incluyendo desde las propuestas de reformas burocráticas weberianas (Evans \& Rauch, 1999), a los análisis de mejora de las instituciones anticorrupción y las que focalizaban en asegurar los derechos de propiedad y estabilidad al sistema jurídico contractual (Rose-Ackerman, 2016), hasta los análisis de la gobernanza en la descentralización fiscal (Huther \& Shah, 1998), entre otros. La idea de "buena gobernanza" se amplió (o infló) al nivel de incluir aspectos del accionar del gobierno en temas como participación, democracia, descentralización, respeto por los derechos humanos, género, equidad racial, legislación climática, seguridad ciudadana, etc. Con razón, no pocos analistas indicaron que eso implicaba un desvío o alejamiento de la discusión central de las instituciones y del concepto propio de gobernanza (Grindle, 2010).

Ahora bien, la materialización de estas ideas o representaciones de la gobernanza fue variada y dependiente de su contexto político, económico e institucional (ver van Lindert \& Verkoren, 2012) y de las fortalezas y/o debilidades de los Estados y sistemas políticos para implementar esas ideas.

En el caso argentino por ejemplo, estas formas de gobernanza emergieron principalmente en el marco de los procesos de reforma sobre el Estado durante fines de los 805 y principios de los 90s. Brevemente, la primera generación de reformas importantes sobre el Estado focalizó -como es sabido- en un fuerte achicamiento de la estructura estatal y una descentralización de funciones hacia las

\footnotetext{
2 La literatura ha discutido ampliamente sobre las definiciones de gobernanza. El lector puede revisar (Börzel, 1998; Hewitt de Alcántara, 1998; Kooiman, 1993; Mayntz, 1998; Messner, 1997) por mencionar algunos de los más citados de la primera generación del debate. Una revisión más actual puede verse en Bevir (2011), Levi-Faur (2012) y Grindle (2007, 2010, 2016).
} 
instancias inferiores fundado en la necesidad de reducir el aparato estatal (gasto nacional), lo que dio paso a que la idea de gobernanza apareciera como una especie de reservorio de la delegación de funciones del Estado, sobre todo a nivel regional. Las siguientes generaciones de reformas en Argentina se ocuparon de intentar mejorar los aspectos técnicos de la provisión de servicios, con mayor énfasis en la subsidiariedad de la intervención, la preocupación por la eficiencia y la eficacia de las acciones estatales.

En ese marco, sobre todo las corrientes de inspiración institucionalista, vieron quizá con buenos ojos a la gobernanza como aquel concepto que representaba la articulación reflexiva entre Estado y sociedad civil que se estaba intentando forjar (ver Burki \& Perry, 1998). A su vez, los posteriores modelos de administración pública orientados por las ideas del gerenciamiento público, con un arsenal conceptual diferente, acompañaron este proceso de mutación del gobierno a la gobernanza, dando mayor relevancia a los mecanismos de implicación de los actores sociales receptores de los bienes y servicios otrora propiciados por el Estado. Así aparecieron y se reafirmaron las ideas de la accountability o rendición de cuentas hacia la sociedad civil, repartiendo la distribución de riesgos y recompensas entre el Estado y los actores no estatales, e incentivando a los ciudadanos (en ocasiones devenidos en clientes) a adquirir mayor responsabilidad por las acciones estatales, sobre todo a nivel local donde se instaba a esta instancia a convertirse en el principal motor para que la sociedad civil participe efectivamente en asuntos que conciernen a sus propios entornos de vida y de producción (de Mattos, 2004).

Reafirmando incluso esa tendencia, más recientemente reapareció la preocupación por la transparencia de la administración pública vinculada ahora a las ideas de gobierno abierto (Concha \& Naser, 2012; Oszlak, 2013) tendiente precisamente a que el Estado pueda ser constantemente interactuado por la sociedad civil en forma -aparentemente- más democrática y reflexiva, y conjugando en definitiva con algunos de los principios básicos de la gobernanza.

Ahora bien, si la gobernanza a nivel nacional en Argentina se desplegó mayormente al amparo de las reformas neoliberales de los gos de achique y "devolución" de funciones por parte del Estado a la esfera social y económica privada potenciada luego por las (aun) incipientes reformas ofrecidas por las orientaciones conceptuales de la nueva gerencia pública, en los debates del desarrollo regional y local, ámbito que nos incumbe aquí, el concepto de gobernanza fue ganando lugar privilegiado a través de una inmensa variedad de expresiones y conceptos regionalistas que intentaban reflejar esta nueva orientación en la forma de gobernar y de emprender proyectos políticos. Concretamente, el planteo regionalista habilitó también un camino hacia la gobernanza desde varios cuerpos conceptuales: por ejemplo, desde los trabajos de las nuevas formas de organización regional de la producción (flexibles) para la generación de riqueza (Piore \& Sabel, 1984), desde los aportes de las ventajas de la proximidad para la reducción de costos de transacción y economías externas (Scott, 1988), desde los análisis de las ventajas de la interacción de los actores económicos como elemento de generación de innovación y aprendizaje colectivo (conocimiento tácito) que podía generar mejoras a nivel de productos y procesos en las empresas facilitado por una infraestructura institucional local que permitiera la circulación de información y mejorara la oferta de servicios empresariales (Cooke \& Morgan, 1998; 
Storper, 1997), entre otros. En ese marco, el regionalismo auspició desde sus comienzos la necesidad de la delegación de funciones desde el Estado central hacia las instancias inferiores para poder avanzar en la apertura del potencial de los territorios como sujetos activos del desarrollo.

En el caso argentino y latinoamericano, el planteo regionalista demandaba revertir la matriz estado-céntrica de estas sociedades ${ }^{3}$. Y prescribía una descentralización de acciones hacia los niveles donde se indicaba que era más oportuna la inclusión de mayores voces posibles y se habilitaba la concertación democrática de los actores intervinientes, al tiempo que se generaban los mecanismos para que esa toma de decisión concertada y esa amplitud de voces, ocurra. Lo local, lo regional, lo territorial, etc. -en ocasiones tratados indistintamente- era visto como la arena quizá más apta para lograr la expresión de voces y la eventual concertación de propuestas. Comenzaron entonces a aparecer expresiones y conceptos como el de gestión estratégica, concertación públicoprivada, articulación de intereses, desarrollo cooperativo, negociación conjunta entre actores sociales, gestión de interacciones, redes locales o mecanismos de coordinación horizontal, gestión territorial, acción colectiva, sinergia social, etc., por mencionar solo algunos de los usos que el lenguaje del desarrollo regional comenzó a adoptar parafraseando a la gobernanza.

Las formas que adquirieron las dinámicas de gobernanza en el marco del desarrollo regional en Argentina fueron variadas. En ocasiones consolidaron en redes informales; a veces solo funcionaban para un proyecto o programa específico (ej., las consultas, plebiscitos, sesiones municipales abiertas, foros temáticos, asambleas, etc.); en otras ocasiones las estrategias de gobernanza aparecían materializadas como instituciones formales que podían incluir una variedad de actores (ej. agencias y/o asociaciones de desarrollo, foros de competitividad empresarial, unidades de vinculación, incluso cámaras empresariales, fundaciones, etc.). No pocas veces estas estrategias de gobernanza poseían gran capacidad para captar fondos de financiamiento (incluso externo) y hasta ejecutaban quizá más fondos que los propios organismos públicos de gobierno, e incluso tenían mayor capacidad técnica-operativa burocrática que las propias oficinas estatales. Las estrategias de gobernanza podían incluir una variedad de áreas temáticas en la prestación de servicios y podían tener articulaciones verticales y horizontales de variada intensidad y geometría institucional.

En la práctica, la planificación del desarrollo regional bajo las dinámicas de gobernanza fue requiriendo una adaptación, al menos desde el Estado, de las herramientas tradicionales de gestión, dando paso a la aparición de una innumerable cantidad de análisis de diagnósticos y de documentos preparatorios de planificación, y una diversidad de desarrollo de manuales de "buenas prácticas", en ocasiones orquestadas desde los organismos de financiamiento internacional que no pocas veces derivaba en un despliegue de formas del tipo "one size fit all" o " $a$ 10-step planning process” (ej. United.Nations, 2008)4 y que dejaba poco espacio para

3 Ver los trabajos regionalistas que auspiciaban la descentralización del Estado de Sergio Boisier (como consultor de CEPAL) que fueran muy influyentes en los debates académicos y políticos en América Latina desde inicios de los 80 (Boisier, 1982, 1987, 1991).

4Ver también http://wbi.worldbank.org/wbi/topic/governance. 
maniobras a los gobiernos regionales y locales para adaptar sus planes a sus propias condiciones contextuales.

Lo cierto es que la combinación de las transformaciones espaciales y morfológicas del Estado, la necesidad de avanzar en la descentralización y empoderamiento a los actores sociales, sumado al fuerte y consolidado emergente regionalista, fueron dando paso a un paradigma muy utilizado en las teorías del desarrollo regional que sustituía la idea de la posibilidad de la activación del crecimiento y el desarrollo económico solo desde "arriba" y solo desde el "Estado", por la idea de la posibilidad de generar los mismos resultados a partir de la dinamización de acuerdos, arreglos, articulaciones, estrategias y multiplicidad de formatos organizacionales o configuraciones institucionales que, a la par del Estado (y en ocasiones suplantándolo), tenían capacidad de generar regulaciones, dinamizar actores económicos, dirigir comportamientos, y encauzar intereses en escalas subnacionales de actuación: el barrio, la ciudad, la región, la metrópolis, etc. (Cardoso Cançado, Tavares, \& Dallabrida, 2013).

\section{Dinámicas de gobernanza para el desarrollo regional en la provincia de Santa Fe (Argentina)}

La provincia de Santa Fe (Argentina) (ver Figura 1), no ha sido ajena a estas estrategias de transformaciones hacia las dinámicas de la gobernanza, sino todo lo contrario. Localizada en la zona central argentina y con una de las economías más importantes del país (segunda en su aporte al PBI nacional y tercera en términos poblacionales) fue epicentro de una serie de dinámicas que convergían en señalar la importancia de la gobernanza regional en las políticas de desarrollo económico regional, e incluso de ejemplificar ese doble proceso direccional de las transformaciones estatales que mencionamos al inicio: el que se producía desde el Estado nacional hacia las instancias inferiores, y desde el propio Estado hacia una mayor articulación con la sociedad civil. Veamos brevemente estas dinámicas (un intento sencillo por graficar estas situaciones se propone en la Figura 2): 
Figura 1. Localización de la Provincia de Santa Fe (Argentina)

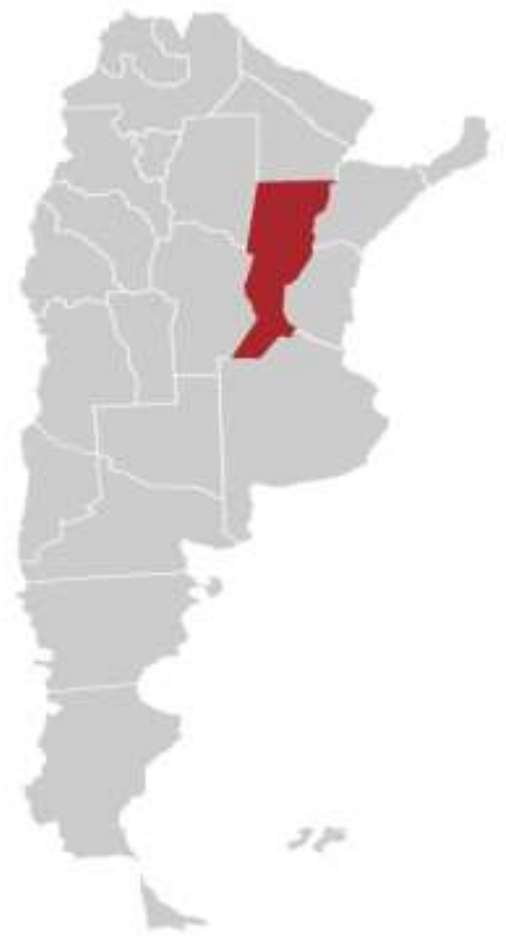

Primero, luego del 2003 desde el Estado nacional se propuso un modelo de acumulación que los economistas llamaron nuevo desarrollismo (como intento de reivindicación moderna del período de sustitución de importaciones de décadas pasadas) (Orovitz Sanmartino, 2009; Varesi, 2010) y que estuvo caracterizado por la aplicación de un paquete relativamente heterodoxo de medidas que incluyó una política monetaria expansiva con cierto equilibrio fiscal, un tipo de cambio más alto (por devaluación) que redefinió la relación interna/externa del sector industrial, y una tendencia (aun con dificultades) hacia un ensayo de reindustrialización de la economía por sustitución de importaciones, con intentos de valorizar al sector productivo por sobre el financiero, con incentivos a la reutilización de la capacidad ociosa y con un fuerte apoyo a la promoción de las pequeñas y medianas empresas (ver Alfini, 2013; Schorr, 2013). Incluyendo también un mayor estímulo a la demanda doméstica, con recomposición del poder de compra de la población (al menos hasta el 2013), subsidios a servicios básicos y una fuerte intervención social universal inclusiva hacia los sectores más vulnerables.

Segundo, en ese planteo "desarrollista" hubo un fuerte impulso a las regiones industriales como fundamento de la mejora de competitividad a partir de fomentar las articulaciones público-privadas: por ejemplo, se aplicaron más de 111 programas de promoción de esquemas asociativos empresario-institucionales a nivel local (sistemas productivos locales, clusters, distritos industriales, etc.) (Naclerio \& Trucco, 2015). Aspectos de la nueva política industrial y regional que fueron expresados en un plan industrial (MI, 2011), un plan de desarrollo (MPFIPS, 2004), un plan nacional de ciencia y tecnología (MCTelP, 2012), y un Plan Estratégico Territorial (PET) (MPFIPS, 2011). 
Tercero, se impulsaron una gran cantidad de "nuevas" iniciativas institucionales que complementaban la acción del Estado en el diseño y ejecución de políticas de desarrollo regional. Entre las más significativas figuraba el impulso dado a las Agencias de Desarrollo Económico Regional (ADERs) (ley nacional $N^{\circ} 25.300$ ) una red de entidades tendientes a mejorar la vinculación del Estado Nacional con las PYMES en la búsqueda de competitividad (ver Figura 3). También emergieron los Foros de Competitividad por sector económico, que articulaban intereses entre los representantes de cada actividad económica y el territorio específico. Se crearon también las oficinas GenIA (Generadores de Industria Argentina) del Ministerio de Industria de la Nación (mini sedes ministeriales) que trabajan para detectar estrategias productivas y planes de inversión con los empresarios locales. Y se reordenaron "viejas" instituciones estatales para orientarse a la promoción de las necesidades regionales como el Instituto Nacional de Tecnología Agropecuaria y el Instituto Nacional de Tecnología Industrial. Todos los cuales intentaban articular a municipios y/o comunas, sociedades rurales, centros económicos locales, empresarios, y una gran cantidad de actores locales en el diseño y ejecución de políticas de regeneración económica regional basada en la gobernanza. 
Figura 2. Esquema de las políticas e instituciones surgidas en los tres niveles estatales para impulsar en Santa Fe (Argentina) la regeneración económica regional a partir de dinámicas de gobernanza en el período nuevo desarrollista (2001-2015)

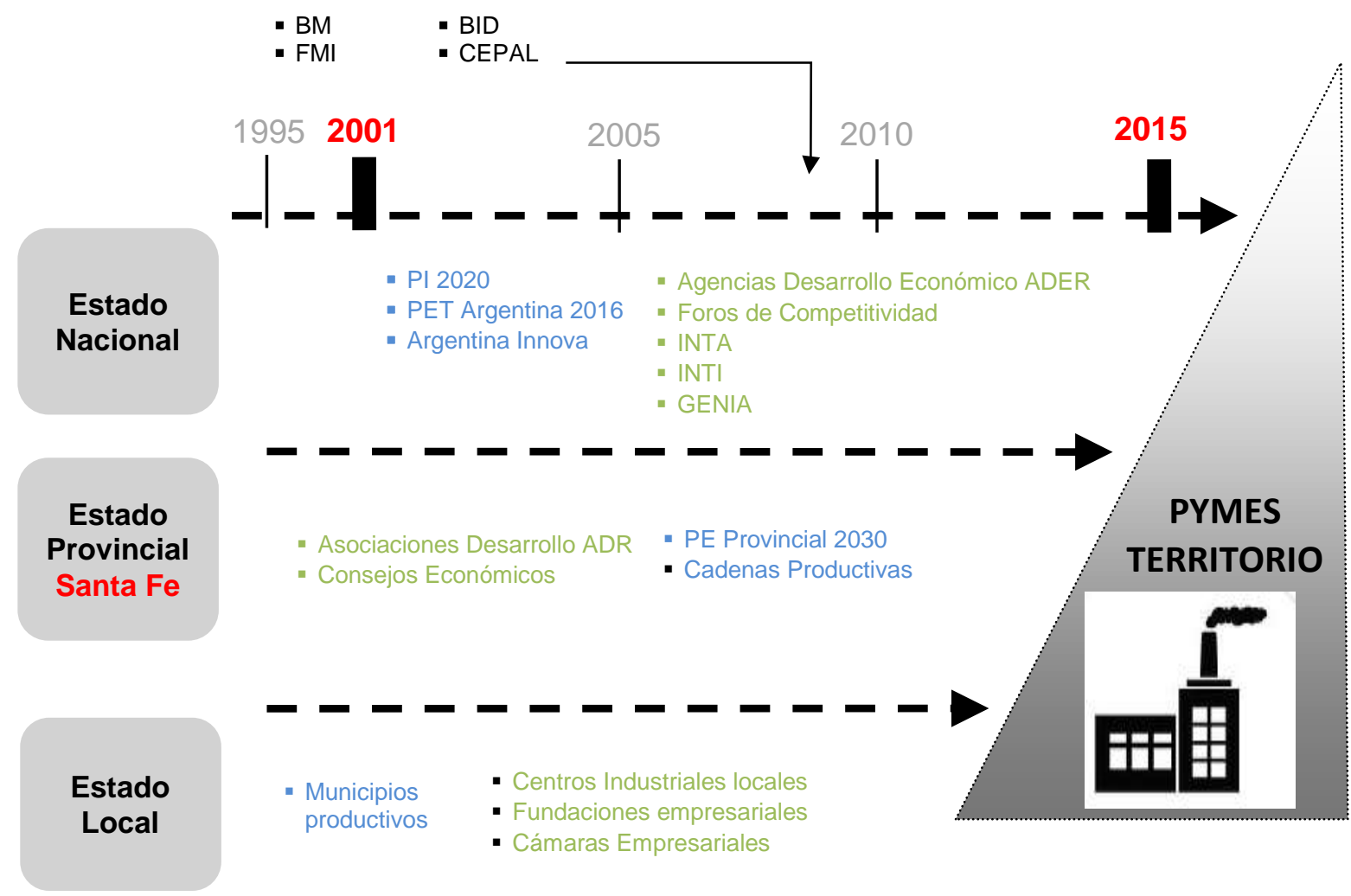

Fuente: elaboración propia (2017).

Por su parte, desde el Estado provincial también han existido en los últimos años aspectos claves que definieron su orientación hacia las políticas de regeneración económica regional en base a las dinámicas de gobernanza:

Primero, desde fines de los $90 \mathrm{~s}$ hubo un fuerte impulso desde el Estado provincial de Santa Fe hacia las denominadas Asociaciones para el Desarrollo regional (ADR); organismos éstos que emergieron como entes autárquicos que manejaban fondos del Estado provincial para desarrollar proyectos de desarrollo regional basados en la articulación del Estado con los agentes económicos locales (empresas). En una clara señal hacia la importancia de las dinámicas de gobernanza regional, la provincia de Santa Fe logró crear un entramado de 19 entidades ADR, cubriendo casi el $60 \%$ de las localidades (ver Figura 3), sobre las cuales se ejecutaron sucesivos programas de apoyo a la producción (ver Ley provincial $\mathrm{N}^{\circ} 2385 / 05$ ).

Segundo, desde el 2008, el Estado provincial puso en marcha un Plan Estratégico Provincial (PEP) "Santa Fe Visión 2030" que impulsó procesos de regionalización y descentralización de políticas públicas para orientar mejor la acción del Estado hacia el sector productivo (Gobierno.de.Santa.Fe, 2008), fortaleciendo nuevamente esas Asociaciones para el Desarrollo a las que definía como organizaciones que generaban sinergias locales y regionales al entramado productivo y marcando la importancia estratégica que tenían las dinámicas de 
gobernanza pública (Bonfatti \& Galassi, 2012, p. 78). A su vez, complementando la articulación público-privada, una de las mayores propuestas del Plan (PEP) era la de regionalización de la provincia, esto es, la conformación de nuevos espacios regionales diferentes de la división jurídico-política tradicional, generándose cinco (5) macro-regiones y/o nodos estratégicos, con instituciones descentralizadas, que redefinirían la manera de hacer política regionalista.

Tercero, también en 2008 se adoptó una nueva forma de planificar la política industrial y regional en base a la idea de "cadena de valor", como una forma de entender el entramado productivo en base al tipo de producto que realiza cada grupo de empresas y de sus vinculaciones hacia atrás y hacia adelante del proceso productivo (proveedores, productores, intermediarios y clientes). La idea habilitó la adaptación de la estructura del Ministerio de Producción regional a esas cadenas de valor para mejorar la inserción del Estado en la comprensión y acompañamiento de esas dinámicas productivas. Y se conformaron a su vez los denominados Consejos Económicos en cada cadena de valor, instancias integradas por instituciones y agentes representativos de cada sector y territorio para diseñar más participativamente políticas específicas (Bertero, 2007, p. 9). Es decir, existieron desde el Estado provincial numerosos hechos tendientes a poner a la gobernanza regional en el centro de la escena para el diseño de políticas 5 .

A su vez, desde mediados de la década del 90 en adelante los Estados municipales de Argentina habían comenzado a implementar transformaciones que incluían una asunción de funciones mayores a las ya tradicionales de "ABL" (Alumbrado, Barrido y Limpieza), creándose por ejemplo en estas instancias estatales las denominadas Secretarías de la Producción ${ }^{6}$, contribuyendo así al proceso descentralizador y asumiendo los municipios un rol importante en el diseño y ejecución de políticas económicas locales, a partir de generar -en línea con el planteo de la gobernanza- redes de actuación horizontal con los actores económicos (fundaciones, cámaras empresariales, sociedades rurales, centros industriales, etc.) (Costamagna, 2007). La figura del secretario de producción respondía a un perfil de articulador local con un fuerte conocimiento del entramado institucional parroquial en el cuál debía operar y con capacidad para crear acuerdos y alianzas de trabajo conjunto en ese escenario. Como dato, para el año 2000 en Santa Fe se habían constituido casi 50 Secretarias de la Producción municipales y casi 20 en las comunas (instancias administrativas inferiores al municipio).

\footnotetext{
5 Como dato, ver también la plataforma electoral del Frente Progresista, Cívico y Social (FPCS), gobierno desde 2007, que planteaba la reforma del Estado "para descentralizarlo y generar nuevas formas de gestión ligadas al modelo de gobernanza, así como la jerarquización de la esfera de lo público no estatal (Programa FPCS, 2007).

6 Creadas a partir de un programa denominado "Municipios Productivos" del Ministerio de la Producción de Santa Fe, y financiado por el Consejo Federal de Inversiones (CFI), una institución federal nacida de un acuerdo interprovincial con la finalidad de financiar estrategias de desarrollo local con eje en las PyMEs.
} 
Figura 3. Ubicación de las Asociaciones (Provincia) para el Desarrollo Regional de Santa Fe y de las Agencias (Nación) de Desarrollo Económico Regional

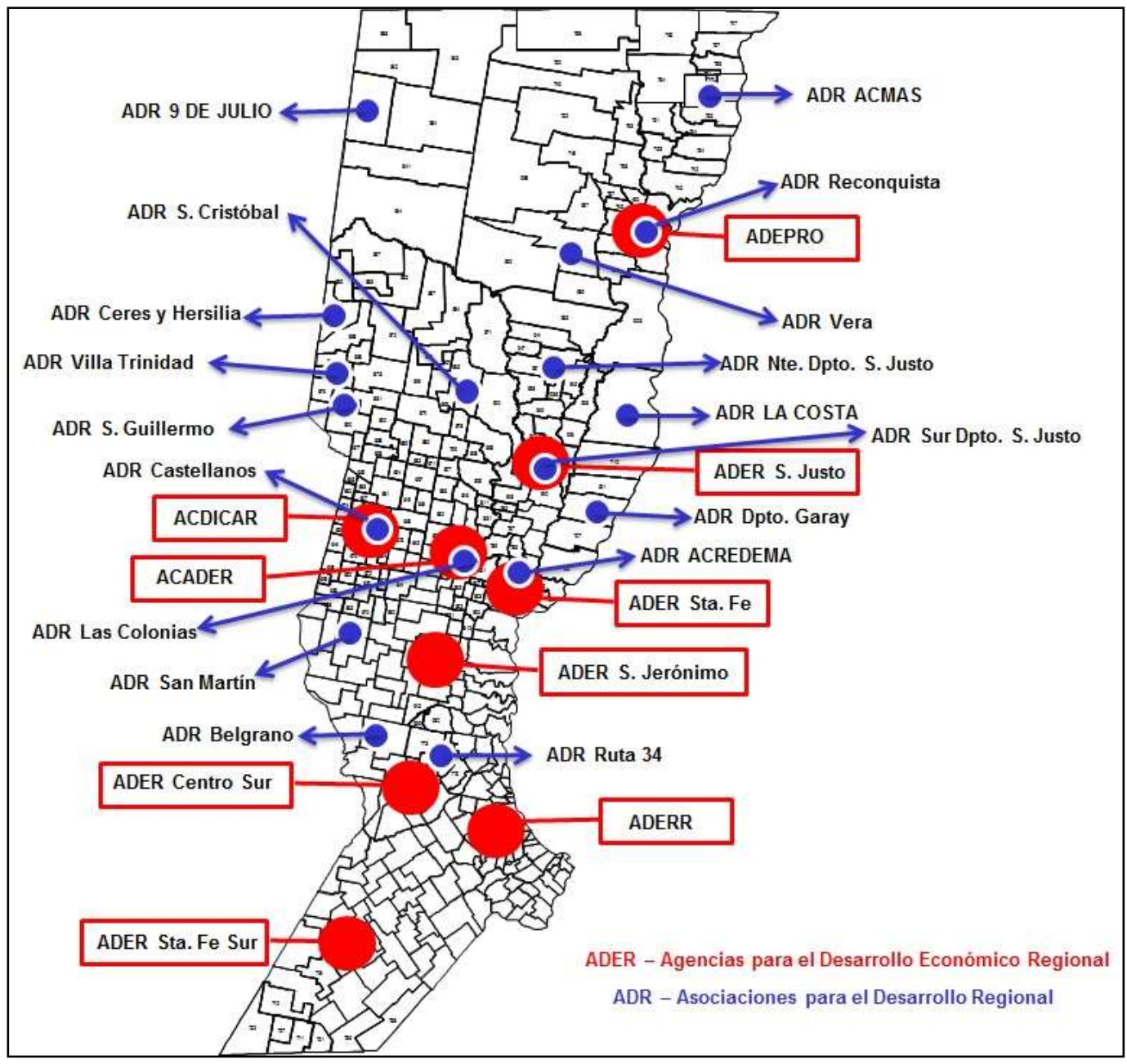

Fuente: elaboración propia (2017).

Ahora bien, ¿por qué decimos que esta situación de multiplicidad de dinámicas de gobernanza surgidas en los últimos años sobre el escenario de la provincia de Santa Fe (Argentina), tanto de políticas como de instituciones provenientes del ámbito nacional o regional, y reorientadas a promover la regeneración económica regional, ha resultado problemática? Y en todo caso, ¿por qué ha sido problemática específicamente para Santa Fe? Mencionamos desde el inicio que exploraríamos tres tensiones a nivel empírico: i)el rol del Estado regional en el auspicio de la gobernanza, ii)la relación entre las geografías de regulación (Estado nacional, regional, local);y iii)el gap entre las ideas políticas sobre el espacio regional de la gobernanza y la concreción de las políticas en el espacio regional. Veamos cada una de ellas. 


\section{Políticas regionales y gobernanza: un estudio exploratorio sobre el caso de la provincia de Santa Fe (Argentina)}

\subsection{Las tensiones vinculadas al rol del Estado como promotor y facilitador de las dinámicas de gobernanza}

La literatura que hemos reseñado advertía sobre las posibles ventajas de las dinámicas de gobernanza para la implementación de políticas económicas regionales, en tanto y en cuanto sea posible contar con un actor (el Estado regional) que fomente y facilite esas instancias de gobernanza (sensibilización, capacitación, difusión, etc.), que coordine esas acciones de articulación en relación a un plan y/o rumbo definido o definible, y que controle (a través de un entorno legal, o de la dirección estratégica, o del direccionamiento del financiamiento, o del monitoreo de acciones, e incluso a través de mecanismos de seducción política) a los actores de la gobernanza y sus interacciones de manera que no se generen lógicas contradictorias o de cooptación de intereses.

Para el caso particular de Santa Fe, como primer estudio exploratorio, una hipótesis que sostendremos es que la intención de empoderar a los actores de la sociedad civil (agentes económicos) no ha pasado de una declaración de intención y no ha logrado terminar de fortalecer verdaderamente a los agentes intermedios (instituciones de apoyo a Pymes), o empoderar a los agentes últimos, los actores económicos (empresas) para ejecutar políticas de desarrollo económico regional.

Por ejemplo, revisando un aspecto central vinculado al financiamiento de las dinámicas de gobernanza, es posible notar que el Estado santafesino se caracterizó por asumir una conducta errática con notoria intermitencia y discontinuidad en el fortalecimiento de estas instituciones intermedias.

Los primeros estudios exploratorios indican que, si bien las Asociaciones (ADRs) eran visualizadas por el Estado como actores "claves" del trabajo en red para el desarrollo territorial, en la práctica han sido escasamente representativos los recursos que se han movilizado para financiar su accionar (Ockstat, 2015). Las Asociaciones (ADRs) obtenían recursos del Ministerio de la Producción de la provincia de Santa Fe, un ministerio que, comparadamente (ver Figura 4), fue de los que menos disponibilidad de recursos tuvo en el gasto público provincial durante el período analizado. En ese marco inicial de poco financiamiento para el Ministerio de la Producción, los recursos destinados a las ADRs también fueron muy escasos (Figura 5). Solamente en 2008 los recursos llegaron a representar un porcentaje medianamente significativo del total disponible en la cartera productiva. Y ocurrió en tanto, en ese año el Estado Provincial debió dar respuesta a una situación extraordinaria de emergencia agropecuaria por fenómenos climáticos (inundaciones o sequías) y cuya asistencia canalizaba a través de las ADRs. Eran desembolsos para paliativos a situaciones de crisis antes que acciones estratégicas de política económica regional. 
Figura 4. Santa Fe (Argentina). Evolución del gasto publico provincial total (\$) comparada con ministerios seleccionados (2006-2014)

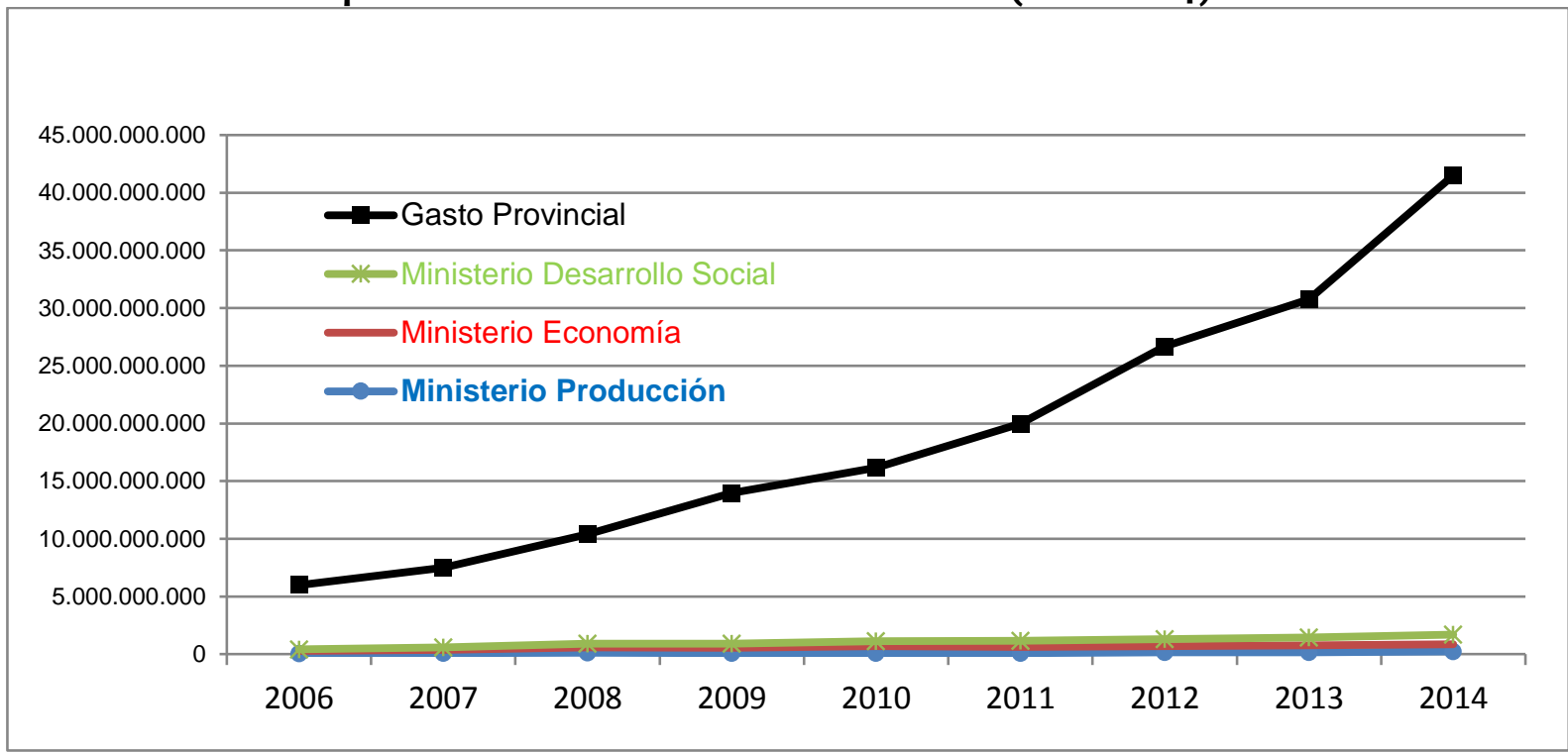

Fuente: elaboración propia en base a Leyes de Presupuesto de la Provincia para los años considerados (2017). Valores corrientes.

Figura 5. Santa Fe (Argentina). Evolución del gasto público provincial (\$) para financiar las Asociaciones para el Desarrollo regional (ADRs). Comparación con gasto total Ministerio Producción provincial (2006-2014)

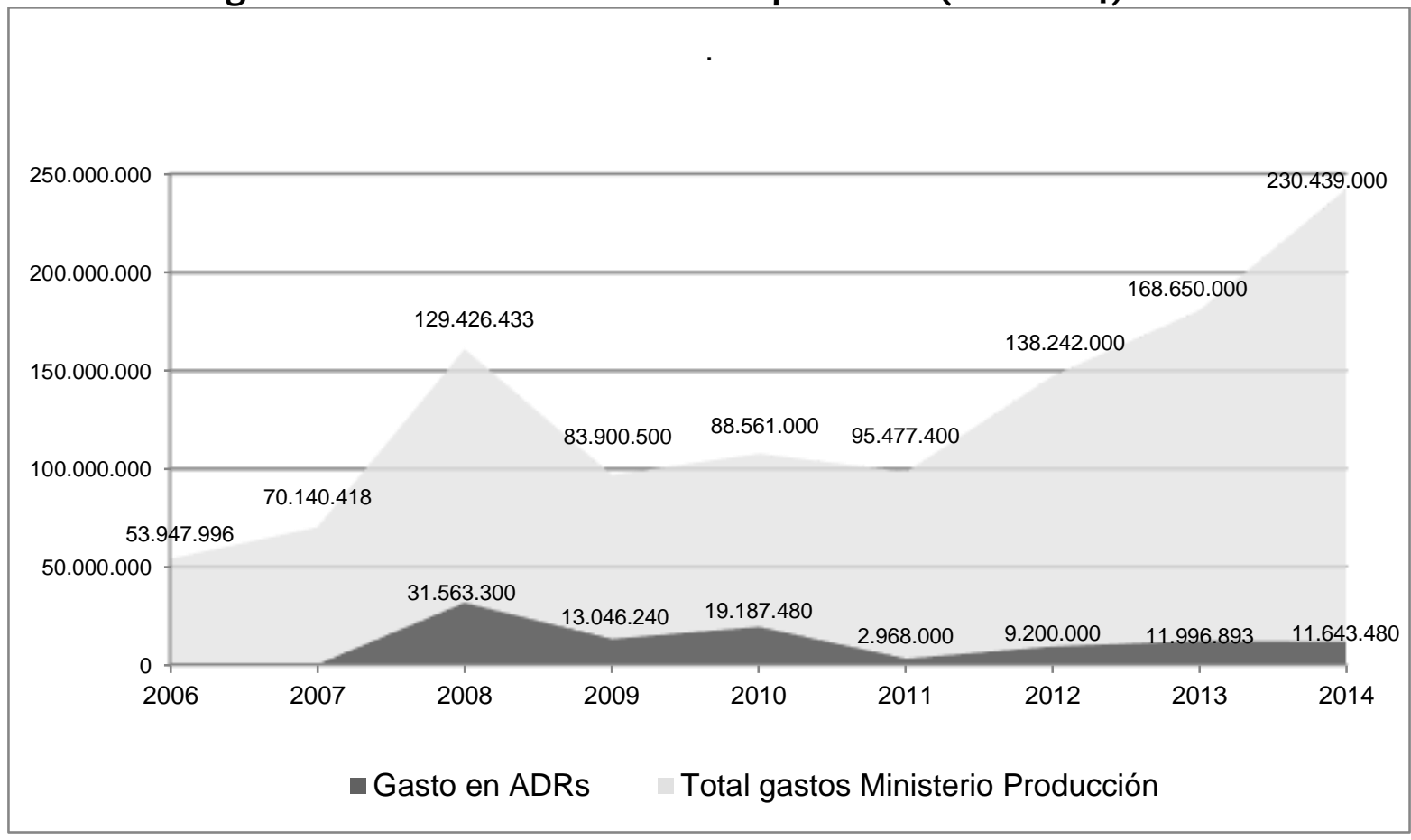

Fuente: elaboración propia en base a Leyes de Presupuesto de la Provincia para los años considerados (2017). Valores corrientes.

Es decir, a pesar de la fuerte presencia simbólica de las asociaciones (ADRs) y de su importancia estratégica para el desarrollo regional de la provincia en el discurso político provincial, éstas han tenido un rol más bien accesorio antes que de 
actores claves para vehiculizar programas y herramientas de apoyo que estimulen un crecimiento en el sector productivo de Santa Fe.

Esta tendencia que en la práctica mostraba la dificultad del Estado para fortalecer las instituciones de la gobernanza quedaba también de manifiesto en la visión de los propios actores institucionales de las ADRs cuando se los consultaba sobre el apoyo estatal. Un estudio preliminar sobre el tema en base a entrevistas a informantes claves indicaba precisamente que esa dificultad estaba dada por la intermitencia del vínculo que el Estado Provincial establecía con las asociaciones (ADRs) (OCKSTAT, 2015). Incluso, los dirigentes de las ADRs, indicaban que el propio Estado provincial parecía por momentos no tener claras expectativas sobre el rol de estas instituciones. Al respecto, resulta esclarecedor un comentario que aparece en una de las entrevistas usadas en estos estudios:

\begin{abstract}
las ADRs son un socio importante, eso te lo dicen siempre, pero: ¿para qué son importantes? Por momentos no queda del todo claro qué quiere hacer el Estado al promover, al incentivar la creación de ADRs. Incluso fortaleciéndolas. No queda del todo claro el sentido que se quiere dar a estas instituciones más allá de ser espacios donde la gente se reúne. Eso es bastante desconcertante, te impide pensar a mediano plazo y te impide tener un ejercicio de cooperación. (Entrevista a informante clave, dirigente de una ADR de Santa Fe, en Ockstat, 2015: 116).
\end{abstract}

\title{
3.2 Las tensiones vinculadas a la falta de coordinación vertical de las políticas entre las diferentes instancias estatales
}

El segundo problema en este proceso de transformación del Estado hacia las dinámicas de gobernanza de múltiples actores y múltiples instancias regulatorias ha estado vinculado precisamente a la falta de coordinación de esas instancias o niveles estatales. Hemos visto que tanto los planes estratégicos nacionales como los planes estratégicos provinciales para Santa Fe han insistido en dar prioridad a la búsqueda de asociatividad público-privada en los niveles inferiores o "territoriales", esto es, a impulsar estrategias descentralizadoras hacia las dinámicas de gobernanza regional o local. Aunque casi sin financiamiento -como vimos en el punto anterior- dichas estrategias de fomento a la gobernanza descansaban principalmente en el potencial parroquial y endógeno de los actores del espacio local y de las articulaciones y mediaciones que los actores económicos, sociales y políticos sean capaces de construir horizontalmente. Según un logrado consenso del mainstream del desarrollo regional ello permitiría desbloquear el potencial "innato" de cada región (otrora constreñido por el asfixio del Estado nacional) para lograr insertarse adecuadamente en los cambiantes procesos de globalización.

Sin embargo, el resultado de dicha estrategia descentralizadora y de empoderamiento a las dinámicas de gobernanza para el caso de Santa Fe fue una explosión de agentes y de complejas articulaciones que generaban redes de actuación (y de representación de intereses) cada cual pujando y compitiendo por re-direccionar procesos de desarrollo regional y local sobre un mismo territorio, y con escasa articulación vertical de instancias reguladoras. Un análisis de caso del período bajo estudio (VIGIL \& PRIOLO, 2014) para la zona central de la provincia de 
Santa Fe ha mostrado estas dificultades indicando, por ejemplo, que durante la implementación de políticas a través de las Agencias para el Desarrollo Regional (dependientes de la instancia nacional) y a través de las Asociaciones para el Desarrollo (dependientes de la instancia provincial) se generaron todo tipo de tensiones.

Por ejemplo, ocurría que la red de vínculos que lograban construir las Agencias (instituciones del ámbito nacional) y las Asociaciones (instituciones del ámbito provincial) actuaba más o menos independientemente una de otra sobre el mismo espacio territorial y sobre la misma área temática, sin articulación horizontal (ej. Figura 6). Por otro, los recursos que provenían del Estado nacional hacia las Agencias de Desarrollo (instituciones regionales pero impulsadas por el nivel nacional) "salteaban" al gobierno regional y local y se articulaban directamente con los empresarios locales y sus fundaciones o asociaciones (Figura 7), e implementaban programas con prioridades impulsadas desde el Estado nacional, como el financiamiento para inversiones productivas de PYMEs con fondos del Banco Central de la Nación Argentina (Financiamiento Productivo del Bicentenario), o las líneas de crédito dirigidas a emprendedores industriales para abrir nuevos mercados (PRODER del Banco Nación), o los créditos blandos para inversión en PYMES del Fondo Nacional para el Desarrollo de la Micro, Pequeña y Mediana Empresa, o la línea de crédito de la Secretaría de Industrias de la Nación (Programa de Acceso al Crédito y la Competitividad), que brindaba asistencia técnica para inversiones, entre otros.

Es decir, la supuesta descentralización del Estado hacia las dinámicas de gobernanza ocurrió paradojalmente obstruyendo la oportunidad que se pretendía generara los Estados locales o municipales (por ejemplo, a través de sus Secretarías de Producción) de conformarse como instancias autónomas y (verdaderamente) descentralizadas para articular actores económicos y resolver problemas de competitividad económico-productiva. Decimos paradojalmente porque el programa político-económico del gobierno regional de Santa Fe desde 2007 hacía especial hincapié en el proceso de fortalecimiento de las instancias inferiores (locales), la potenciación de la iniciativa local, el asociativismo y las dinámicas de redes entre actores del territorio (ver Bonfatti \& Galassi, 2012, p. 75).

Sin embargo, las instancias inferiores del Estado parecían quedar reducidas a acoplarse a las propuestas de políticas y programas de los financiadores de esas agencias (para el caso del Estado Nacional) y de las asociaciones (para el caso del Estado Provincial). Y les generó otro conocido problema vinculado a la necesidad de alineación política de las instancias inferiores con el gobierno superior de turno para obtener recursos financieros para sus territorios. 
Figura 6. Representación de la red de vínculos de Asociaciones y Agencias en la provincia de Santa Fe

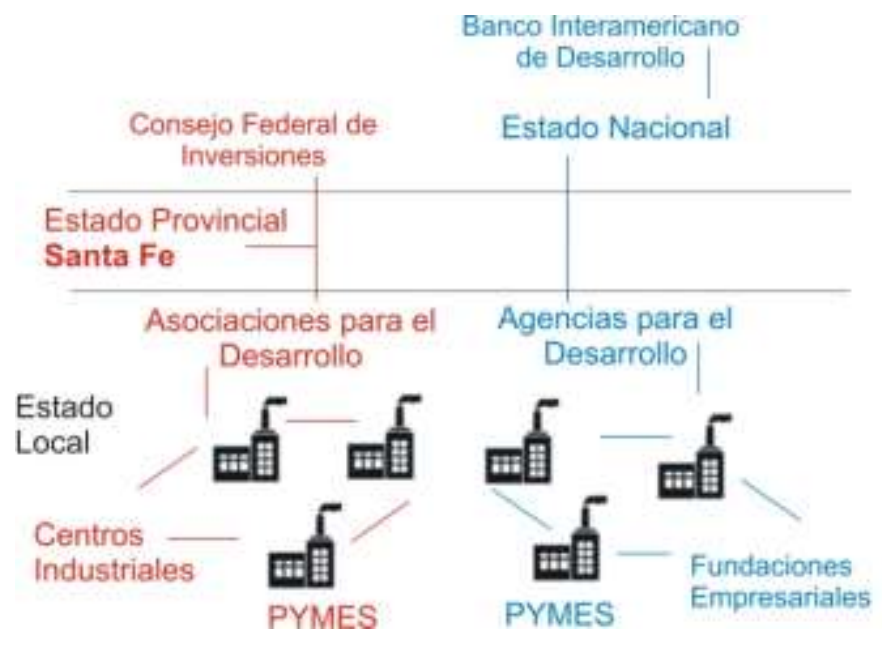

Fuente: elaboración propia (2017).

Figura 7. Representación del salto al Estado regional por las agencias de desarrollo del Estado nacional

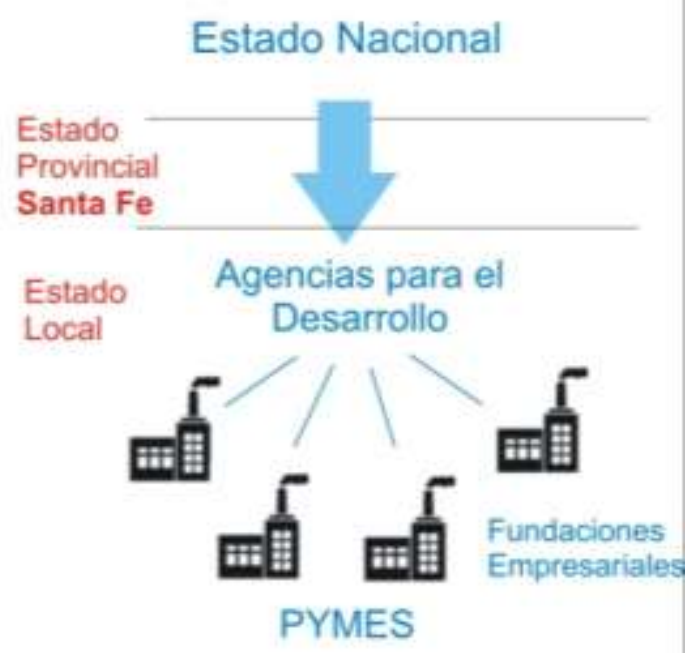

Fuente: elaboración propia (2017)

Otro indicio de esta complejidad irresuelta en la falta de coordinación vertical para el caso de Santa Fe en la misma época de análisis fue visualizada en la relación entre política sectorial y política regional. Por ejemplo, mientras que desde el Estado nacional se impulsaban para la provincia de Santa Fe los esquemas asociativos del tipo aglomeraciones productivas, en cualquiera de sus manifestaciones 
conceptuales más conocidas7, desde uno de los organismos autónomos del propio Estado Nacional (el Instituto Nacional de Tecnología Agropecuaria, INTA), y que encaraba las estrategias de gobernanzaterritorial de articulación de actores para la política agropecuaria, no se veía con buenos ojos la política de aglomeraciones productivas para Santa Fe, y en referencia a esos programas se indicaba:

[la] alta concentración de las fábricas y proveedores en la provincia de Santa Fe [fruto de la política de impulso a las aglomeraciones productivas], no contribuye al desarrollo territorial que se busca [...] (Bragachini, 2008, para el INTA).

La tendencia hacia la implementación de políticas de regeneración económica regional basadas en las dinámicas de gobernanza mostró -como documentamos en esta secuencia de indicios- tensiones en la articulación de las instancias estatales.

\section{Las tensiones vinculadas a la distancia entre las ideas políticas sobre el espacio regional de la gobernanza y la concreción de las políticas en el espacio regional.}

La cuestión sobre la conformación de los espacios regionales fruto de las dinámicas de gobernanza aun ha sido poco estudiada en la literatura de la gobernanza. Esto es, la manera en que las nuevas articulaciones de la gobernanza iban dando paso a la aparición de innumerables formas espaciales relacionales. Por ejemplo, la literatura comenzó a reconocer las formas espaciales emergentes de la articulación de consorcios intermunicipales para la gestión asociada de servicios públicos (ver Brandão, 2011), o las formas regionales de las aglomeraciones de empresas de variada intensidad y geografía, o las formas espaciales provenientes de los corredores de comercio, o de la diversidad de cadenas de agregación de valor, o de regiones transfronterizas, corredores bioceánicos, incluso de redes de prácticas (de profesionales, de técnicos, de comerciantes, etc.) que llegaban a tener asentamientos espaciales temporales (configuraban aglomeraciones territoriales circunstanciales a partir de conferencias, ferias, exhibiciones, congresos, etc.) (Amin \& Roberts, 2008; Harrison, Smith, \& Kinton, 2017; Maskell, Bathelt, \& Malmberg, 2006) y hasta configuraciones espaciales generadas a partir de las denominadas relaciones de ciudad a ciudad (hermanamientos entre partes iguales) que promovían intercambios útiles (culturales o de capacitación para empresas o entre universidades o centros de transferencia) (Bontenbal, 2009). En el ámbito del desarrollo regional un fuerte impulso a estas nuevas configuraciones espaciales lo dio la literatura vinculada a la innovación y el aprendizaje que sugería que esas configuraciones podrían provenir de dinámicas no locales o distantes (Gertler, 2008) y por tanto deberían fomentarse prácticas que abran la dinámica de interacciones y conexiones hacia eventuales redes des-localizadas.

Lo cierto es que a medida que se consolidaban estas interacciones iban dando lugar a nuevas configuraciones espaciales relacionales con reclamos de

\footnotetext{
7 Por ejemplo, el Ministerio de Industrias de la Nación lo hacía a través de un programa pro-clusters financiado por el Banco Interamericano de Desarrollo (Naclerio\&Trucco, 2015; SSePyMEyDR, 2005) y el Ministerio de Agricultura de la Nación lo hacía a través de un programa pro-distritos industriales (ver Moltoni, 2014).
} 
intereses (sobre infraestructura, transporte, movilidad, seguridad, consumo, logística, etc.) y con capacidad de presión para atraer y conquistar políticas públicas para esas nuevas configuraciones espaciales generadas, y que muchas veces generaban nuevos desafíos a las formas de gobierno tradicional de la geografía de las divisiones jurídico-políticas y territoriales.

Ahora bien, en buena medida, el Estado de la provincia de Santa Fe pareció entender estas nuevas dinámicas de la espacialidad y la gobernanza, y hubo durante la segunda mitad de los 2000 s un intento (quizá el más importante de la historia de la provincia de Santa $\mathrm{Fe}$ ) por reconstruir y re-caracterizar la espacialidad políticoeconómica provincial para el desarrollo de políticas de regeneración económica regional atendiendo a algunas dinámicas de gobernanza que se venían dando, y a otras dinámicas que pretendía fortalecer. Sin embargo, existieron muchos bemoles en la vinculación entre la política y la práctica, y el gap entre la declaración y la acción volvió ineficiente a la gobernanza.

Ejemplo 1: con la aparición en 2008 del Plan Estratégico Provincial (PEP) de Santa Fe (GOBIERNO DE SANTA FE, 2008) se avanzó hacia un proceso de regionalización que -como vimos- dividió la provincia en espacios socio-económicos, cada cual concebido como "... un sistema flexible, de fronteras dinámicas y permeables que reconstruyen los itinerarios de los actores locales y regionales..." (BONFATTI \& GALASSI, 2012, p. 182); lo que para algunos observadores aparecía como una novedosa mirada relacional en la conformación del espacio regional (ej. SIGNORELLI, 2013). Casi diez años después de implementado, el planteo formal de regionalización se mantuvo, e incluso las regiones fueron dotadas de una estructura estatal para funcionar (ej. Oficinas de Coordinación Regional, u Oficinas de Planificación y de Gestión territorial, en cada región "creada”). Sin embargo, en la práctica la división de las regiones solo ha funcionado en estos diez años para que las estructuras estatales diseñadas para funcionar en su nombre dialoguen y discutan con los actores sociales, pero en términos "concretos" no ha terminado de materializarse ninguna política que justifique la regionalización propuesta.

Incluso en su actualización en 2012 el PEP insistía en la idea de una provincia "conectada" (BONFATTI \& GALASSI, 2012, p. 165 ss) dentro de lo que se incluiría como aspecto central una revisión de la infraestructura vial, el desarrollo portuario y fluvial, una reconversión ferroviaria, y una mayor integración aerocomercial; y se proponía partir de un Estudio Integral de la Logística de Cargas que releve la situación actual y la identificación de demandas, flujos, corredores y necesidades, permitiendo la definición de estrategias para el desarrollo provincial. Se reconocía incluso la importancia de la incorporación del concepto de espacio geográfico en la administración pública provincial a partir -entre otras cosas- de auspiciar la incorporación de tecnologías geoespaciales a través de la Infraestructura de Datos Espaciales de la provincia de Santa Fe $\left(\right.$ IDESF) ${ }^{8}$, como apoyo en la planificación y la gestión de políticas públicas para el desarrollo de los territorios (BONFATTI \& GALASSI, 2012, p. 176). Sin embargo, los avances en materia espacial desde el Estado

\footnotetext{
8 Establecida por el Decreto $N^{\circ} 1680 / 2005$, la Infraestructura de Datos Espaciales de Santa Fe es el conjunto de recursos tecnológicos que facilitan la producción, obtención, uso y acceso de información geográficamente referenciada de cobertura provincial, organizada para asistir a la toma de decisiones (mapas, base de datos, metadatos, etc.).
} 
provincial son escasos y muchas de las cuestiones mencionadas están aún en etapa embrionaria (BONFATTI \& GALASSI, 2015).

Más aun, el Estado provincial ha mantenido las delimitaciones tradicionales por departamento para la implementación de buena parte de sus programas y políticas, o bien ha creado nuevos espacios regionales, como en el caso de la instrumentación del Plan del Norte (Decreto $\mathrm{N}^{\circ}$ : 0015/2016) tendiente a revertir el retraso relativo del norte provincial y que ideó una nueva configuración espacial con nuevas instituciones especificas a esa configuración espacial (ver Figura 8).El plan del norte contiene más de 130 proyectos, consensuados con múltiples actores públicos y privados del territorio, que contemplan obras de infraestructura, políticas productivas y la implementación de proyectos y programas sociales, en las áreas de educación, salud, vivienda, medio ambiente, cultura, deportes y seguridad.

Figura 8. Regionalización jurídico-política de la provincia de Santa Fe (izquierda), regionalización de Santa Fe según el plan estratégico 2008-2012 (centro) y regionalización del norte de Santa Fe según Plan del Norte 2017 (derecha).

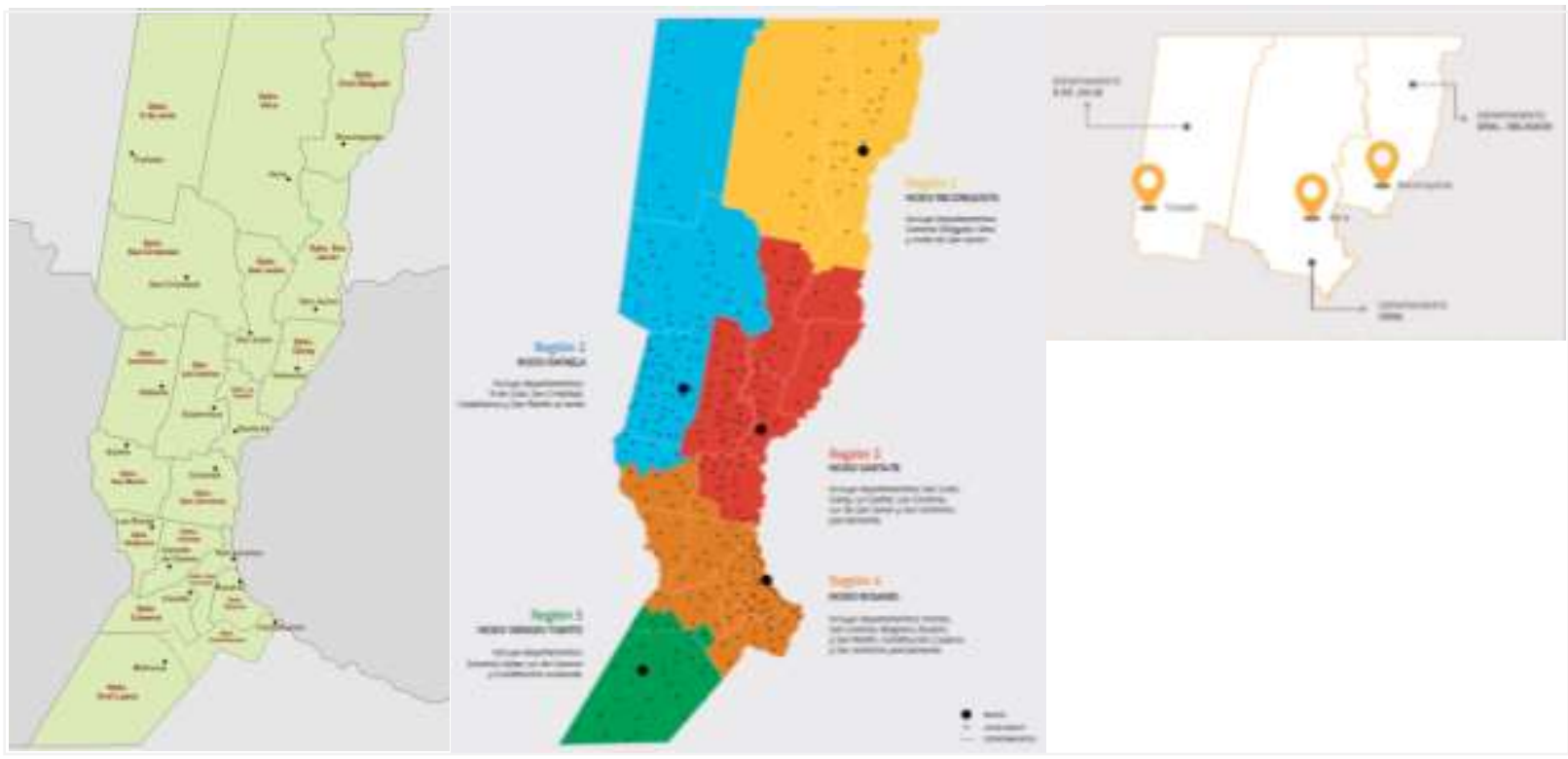

Fuente: Plan Estratégico Provincial de Santa Fe (2012) y Plan del Norte (1er Informe de Avances, Febrero 2017).

Ejemplo 2: desde el año 2007 la provincia de Santa Fe comenzó a plantear una reestructuración de su política productiva tomando como base el concepto de sistema productivo regional yel decadena de valor (en lugar de sectores económicos) lo que permitía considerar la dinámica espacial de las relaciones económicas a partir de las interacciones de los actores con intereses comunes, y repensar desde allí políticas de regeneración económica regional específicas a esas dinámicas espaciales (ej. infraestructura, transporte, etc.). El planteo despertó mucha expectativa para generar una mayor y mejor integración social, sectorial y territorial de Santa Fe. El planteo motivó incluso la reestructuración del Ministerio de la Producción provincial, para adaptarlo a la dinámica de las cadenas de valor regionales, y se conformaron -como mencionamos al inicio-los denominados 
Consejos Económicos de Cadenas de Valor, querepresentan la instancia para garantizar la participación ordenada y permanente de los actores que representan cada Cadena de Valor, quienes a su vez aportarían el conocimiento "local" y trasladarían al Estado las demandas y necesidades institucionales y regionales para diseñar adecuadamente políticas específicas, consensuadas y con participación ciudadana (revirtiendo la tendencia top down) (Figura 9).

Figura 9. Ejemplificación de la conformación de las áreas de trabajo del Ministerio de la producción en base a la idea de sistemas productivos y cadenas de valor

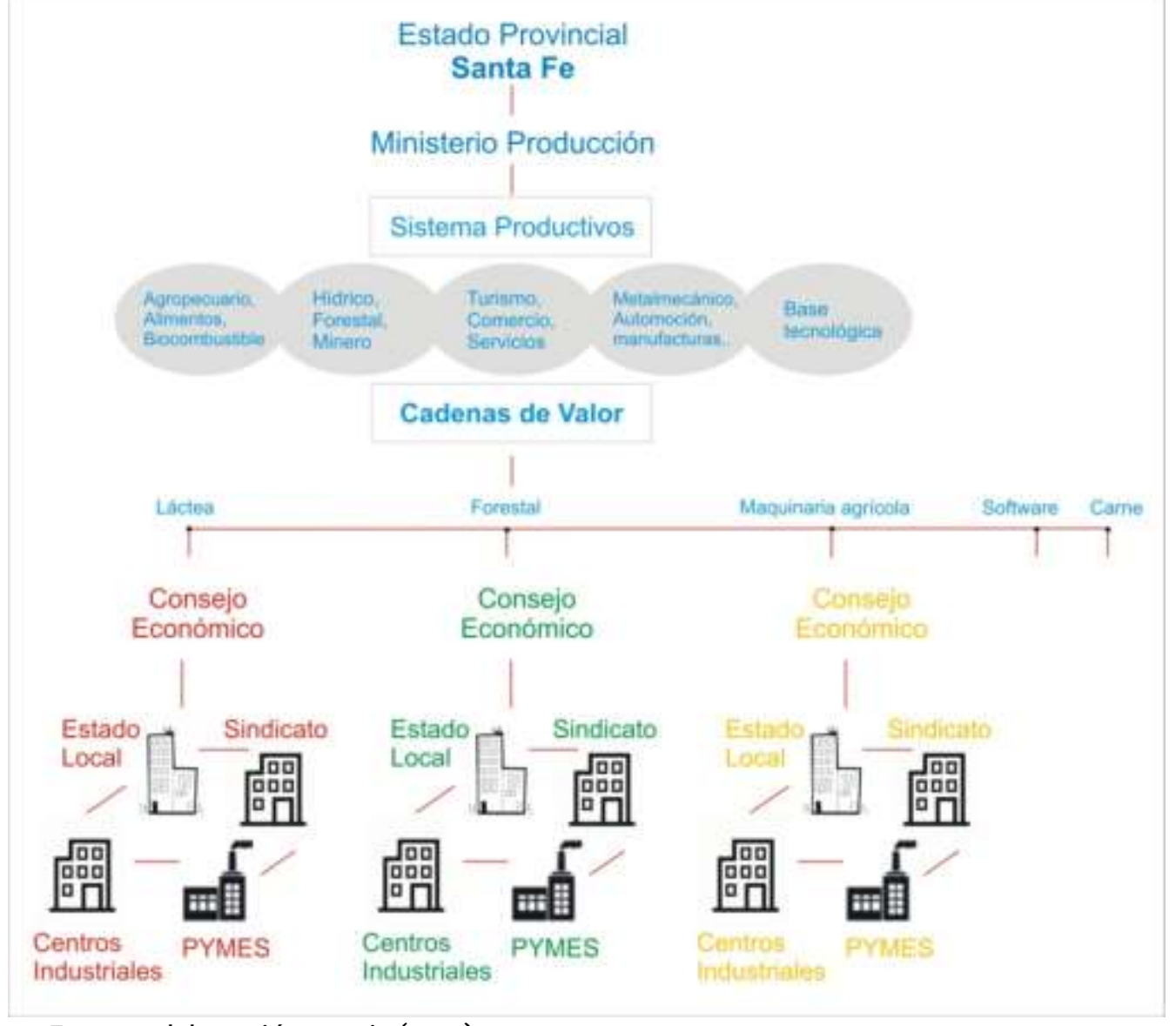

Fuente: elaboración propia (2017).

En el terreno práctico, salvo muy contadas excepciones dichos Consejos Económicos exhibieron un rol bastante magro en relación a la política productiva provincial, en algunos casos su existencia se diluyó en el tiempo y en otros casos no lograron siquiera constituirse. Más aún, en algunas cadenas de valor estos Consejos Económicos funcionaron como lugar de recepción de problemáticas y demandas por parte de la sociedad civil, de los actores locales institucionales y económicos, demandas que a su vez sobrepasaron la capacidad y posibilidad por parte del Estado provincial para atenderlas directamente o bien encausarlas (Ockstat, 2015). Pero más allá de algunas cuestiones puntuales y de actualización de algunos diagnósticos sobre la realidad de cada sector, la participación de los Consejos Económicos en la configuración de la política provincial y en la definición de las políticas espaciales 
regionales -el objetivo de su implementación- ha sido bastante acotada. Y más aún, las dinámicas de gobernanza regionales no han logrado coordinarse adecuadamente con las instituciones macro nacionales en torno a políticas adecuadas para solucionar problemas estructurales.

Dos casos son significativos en la provincia de Santa Fe de la distancia entre la idea de la política y su efectividad. El caso del Consejo Económico vinculado a la producción del algodón (producción muy importante en la provincia de Santa Fe, que registra 384 productores algodoneros) no funcionó eficientemente como un dinamizador de políticas. Por ejemplo, el Consejo Económico trazó un plan estratégico en 2010 con un interesante diagnóstico inicial que indicaba un mercado poco transparente y muy distorsionado para la actividad (ver Ministerio Producción Santa Fe, 2010). Sin embargo, recién en 2016 y fruto de la sanción de la Ley Nacional $\mathrm{N}^{\circ} 26.060$ de Fomento a la Producción Algodonera (ley a la que adhirió la provincia) se logró obtener financiamiento para la aplicación de un programa de mejora de la "trazabilidad" de la producción del algodón santafesino (certificar la calidad de la producción durante todo el proceso de agregado de valor), con un proyecto de formación de clusters industriales proveniente del Ministerio de Industria de la Nación (con fondos del Banco Interamericano de Desarrollo) y coordinado por la Asociación para la Promoción de la Producción Algodonera (APPA). Como muchos de los programas de este tipo, los objetivos son fijados nacionalmente.

En el caso de la cadena láctea, la activación del Consejo Económico permitió que las dinámicas de gobernanza actuaran bien no solo como detectores capilares de las de demandas económico-territoriales, como suele indicar la definición misma de la gobernanza, sino como canalizadores de esas demandas hacia las instancias superiores (nacionales) con capacidad de gestionar la resolución. Concretamente, la creación del Consejo Económico lácteo puso en evidencia un problema vinculado a la formación de precio de los productos lácteos (sobre todo en el costo de la leche). Ese diagnóstico permitió luego requerir al Estado provincial la implementación de un mecanismo de generación de información que permita transparentar el proceso de producción y formación de precio y fijar precios de referencia de lo que podría (debería) cobrar un productor en tranquera frente a quien le compra la leche para industrializarla. El mecanismo piloto implementado por el Estado de Santa Fe (y otras provincias lecheras) para obtener precios de referencia fue evolucionando hasta habilitar en la legislación nacional un sistema de pago al productor basado en la calidad de la leche 9 por el cual los operadores deben enviar a analizar muestras de leche cruda de cada productor y de acuerdo a los resultados obtenidos en el laboratorio realizan la liquidación de pago única, obligatoria y universal que entregan a los tamberos (el $70 \%$ de la leche se paga según este sistema). El mecanismo evitó así que los operadores y/o supermercadistas sean formadores unilaterales de precio.

\section{Repensando la relación entre Gobernanza, Estado y políticas regionales.}

Como vimos, el debate sobre las dinámicas de gobernanza ha sido rico y tiene ya una cierta madurez, tanto en sus elementos puramente teórico conceptuales como en sus discusiones empírico-practicas, ya sea dentro de la esfera

9 Resolución 229/2016 el “Sistema Integrado de Gestión de la Lechería Argentina” (SIGLeA) 
de la ciencia política y sus relaciones con las teorizaciones sobre el Estado y las políticas públicas como dentro de las corrientes vinculadas al desarrollo regional y la geografía política. A partir de esa madurez, planteamos que existían aun algunas problemáticas importantes y propusimos analizarlas para el caso concreto de Argentina en una provincia importante (Santa Fe) que había hecho gala de las potencialidades de las dinámicas de gobernanza en la regeneración económica regional. Vimos algunos problemas de la articulación de instancias de regulación, de la debilidad del acompañamiento del Estado regional en las dinámicas de gobernanza regional, y una notoria distancia entre el diseño político y la práctica vinculada a la espacialidad de las dinámicas de gobernanza.

El planteo que hemos hecho no hace sino advertir un debate muy actual presente en la academia, y en particular en la geografía política (ver Agnew, 2015; Jessop, 2016; Jones, 2016) que tiende a revisar la manera en que se han diseñado e implementado políticas regionales basadas en las (supuestas) ventajas de las dinámicas de gobernanza. Con el estudio de caso como primer análisis exploratorio que sirve de disparador de la discusión, y con eje en el debate que plantea la revisión de la gobernanza, tres aspectos creemos que pueden ser centrales para rediscutir en la política regionalista argentina:

Primero, es cierto que no pocos estudios han mostrado que las dinámicas de gobernanza pueden funcionar muy bien en el delivery de la política incluso sin la presencia coordinadora de un actor estatal fuerte (esto es, evitando lo que la bibliografía especializada llama "governance in theshadow of hierarchy"). Los estudios en esta línea han indicado que los Estados fuertes no son propensos a cooperar con actores civiles (pues aparentemente no estarían dispuestos a resignar autonomía si tienen capacidad suficiente para actuar por su propia cuenta). Por el contrario, es cuando los Estados son aparentemente débiles que más necesitan la acción no estatal para lograr un resultado exitoso en el delivery de su política. Paradojalmente, el dilema en esta opción del Estado débil es el riego de la "anarquía" de las dinámicas de gobernanza (Börzel \& Risse, 2010), como creemos haber mostrado en este trabajo que ocurrió para el caso Argentino. El remedio (múltiples dinámicas de gobernanza) entonces es peor que la enfermedad (Estado coordinador), al menos en estos contextos.

Segundo, las supuestas dinámicas anárquicas que generan las redes de gobernanza, esto es la multiplicidad (de superposiciones, contradicciones y repeticiones) de redes de conexiones, locales, regionales, nacionales e internacionales que atraviesan los diferentes espacios territoriales (centros urbanos, económicos, productivos o culturales que suelen concentrar recursos, población y atención, como vimos para Santa Fe, Argentina), no debería impedir la posible presencia, aun con sus fallas, de un Estado (fuerte) coordinador de políticas que sopese esa anarquía. Siempre y cuando pueda repensarse una morfología poli céntrica para ese actor estatal coordinador. $Y$ este es un aspecto poco explorado aun en la literatura regionalista. En ocasiones esta idea de las dinámicas reguladoras poli céntricas se ha restringidoo limitado a un planteo de equiparación de los niveles de gobierno,es decir, de equilibrio de las funciones del ámbito nacional, del regional y del local, donde generalmente se tiende a criticar la presencia asfixiante del Estado nacional sobre los espacios regionales que reclaman mayor capacidad de 
acción (y para ello, mayor descentralización). Sobre todo si, como vimos, el planteo de la asfixiaproviene del regionalismo.

Sostendremos sin embargo, que el contexto argentino demanda quizá una política regionalista con un actor estatal morfológicamente repensado, en vez de conceptual y políticamente evitado. Existe un acaudalado apoyo conceptual hacia las ventajas de la presencia de los Estados regionales coordinadores de sus dinámicas de gobernanza regional. Y más aún, existe suficiente evidencia sobre la necesidad, sobre todo en América latina y Argentina, de contar con un Estado nacional generador de políticas regionales (ver Vigil, 2015): éste es el actor a quien le corresponde -junto con las regiones- definir la composición general de la actividad económica nacional (el patrón general de acumulación, y sus características) para compatibilizarlo en una estrategia nacional regionalista. Como hemos venido mostrando, las dinámicas de gobernanza tienen una doble función: son la vinculación del Estado con la sociedad civil para "nutrirse" de los conocimientos (y demandas) necesarios para diseñar la política pública, pero también sirven de nexo entre el Estado y la sociedad para hacer más efectivoel "delivery" de las políticas. En cualquier caso, la presencia estatal es indiscutida, y la mayor efectividad de las políticas a través de las dinámicas de gobernanza será posible en tanto y en cuando sean diseñadas y fomentadas por un Estado (regional y nacional) que sepa coordinarse verticalmente.

Tercero, debería re-teorizarse la política regionalista partiendo de una mayor comprensión de las diferentes formaciones socio-espaciales regionales que pueden emerger fruto de las dinámicas de gobernanza (ej. consorcios intermunicipales, aglomeraciones de empresas, corredores de comercio, cadenas de valor, circuitos de producción, regiones transfronterizas, corredores bioceánicos, redes de prácticas, hermanamientos, etc.) como demandantes de intereses (sobre infraestructura, transporte, movilidad, seguridad, consumo, logística, etc.). La posibilidad de diagnosticar diferentes conformaciones socio-espaciales regionales, sobre todo económicas, las características de sus actividades económicas específicas, los niveles de evolución de sus sistemas productivos y la manera en que se integran (o pueden hacerlo) con un patrón general de acumulación (regional y nacional) es central para definir las políticas regionales. Y como vimos para el caso empírico, la debilidad de este punto fue que el intento no terminó de concretarse.

\section{REFERENCIAS}

Agnew, J. Unbundled territoriality and regional politics, Territory, Politics, Governance, 3(2), 119-123, 2015.

Alfini, F. (ed.). Programas y Beneficios para la Industria Argentina.Guía 2013. Buenos Aires: Ministerio de Industria de la Nación / PNUD, 2013.

Amin, A., \& Roberts, J. The Resurgence of Community in Economic Thought and Practice' in A. Amin \& J. Roberts (eds), Community, Economic Creativity, and Organization: Oxford University Press, 2008. 
Bertero, J. J. Adecuación de la Estructura Orgánica y Operativa. Santa Fe: Ministerio de la Producción. Gobierno de Santa Fe, 2007.

Bevir, M. The SAGE Handbook of Governance. London: SAGE, 2011.

Boisier, S. Politica económica, organización social y desarrollo regional, Cuadernos del ILPES (Vol. 29). Santiago de Chile: ILPES, 1982.

Boisier, S. Ensavos sobre descentralización y desarrollo regional. Santiago de Chile: CEPAL, 1987.

Boisier, S. La descentralización: un tema confuso y difuso. In D. Nolhen (ed), Descentralización política y consolidación democrática. Caracas: Nueva Sociedad, 1991.

Bonfatti, A., \& Galassi, R. Plan Estratégico Provincial Santa Fe. Visión 2030. Santa Fe: Ministerio de Gobierno y Reforma del Estado de la Provincia de Santa Fe, 2012. Bonfatti, A., \& Galassi, R. Plan Estratégico Provincial Santa Fe. Visión 2030 / Avances 2008/2015. Santa Fe: Ministerio de Gobierno y Reforma del Estado de la Provincia de Santa Fe, 2015.

Bontenbal, M. Cities as partners. The challenge to strengthen urban governance through North-South city partnerships. Delft: Eburon, 2009.

Börzel, T. A. Organizing Babylon. On the different conceptions of policy networks, Public Administration, 76, 253-273, 1998.

Börzel, T. A., \& Risse, T. Governance without a state: Can it work? Regulation \& Governance, 4, 113-134, 2010.

Bragachini, M. Crecimiento sostenido de la Maquinaria Agrícola Argentina. Mercado interno y exportaciones: Instituto Nacional de Tecnología Agropecuaria INTA Manfredi, 2008.

Brandão, C. A. Descentralização enquanto modo de ordenamento espacial do poder e de reescalonamento territorial do estado. Trajetória e desafios para o Brasil. pp. 115-136 in V. R. Dallabrida (ed), Governança territorial e desenvolvimento. Río de Janeiro: Garamond, 2011.

Burki, S. J., \& Perry, G. E. Más allá del Consenso de Washington: la hora de la reforma institucional. Washington D.C.: Banco Mundial, 1998.

Cardoso Cançado, A., Tavares, B., \& Dallabrida, V. R. Gestão Social e Governança Territorial: interseções e especificidades teórico-práticas, Revista Brasileira de Gestão e Desenvolvimento Regional 9(3), 313-353, 2013. 
Concha, G., \& Naser, A. (eds.). El desafío hacia el gobierno abierto en la hora de la igualdad. Santiago de Chile: Instituto Latinoamericano y del Caribe de Planificación Económica y Social (ILPES). Comisión Económica para América Latina y el Caribe (CEPAL). 2012.

Cooke, P., \& Morgan, K. The associational economy. Firms, regions and innovation. New York: Oxford University Press, 1998.

Costamagna, P. Políticas e instituciones para el desarrollo económico territorial. El caso de Argentina. Santiago de Chile: Instituto Latinoamericano y del Caribe de Planificación Económica y Social (ILPES). Área de Gestión del Desarrollo Local y Regional. CEPAL, 2007.

de Mattos, C. A. De la planificación a la governance: implicancias para la gestión territorial y urbana', Revista Paranaense de Desenvolvimento, 107(Julio-Diciembre), 9-23, 2004.

Evans, P., \& Rauch, J. Bureaucracy and Growth: a Cross-National Analysis of the Effects of 'Weberian', State Structures on Economic Growth, American Sociological Review, 64, 1999.

Gertler, M. S. Buzz Without Being There? Communities of Practice in Context. in A. Amin \& J. Roberts (eds), Community, Economic Creativity, and Organization: Oxford University Press, 2008.

Gobierno de Santa Fe. Plan Estratégico Provincial Santa Fe: cinco regiones una sola provincia. Santa Fe: Gobierno de la Provincia de Santa Fe, 2008. Disponible en: http://www.santafe.gov.ar/archivos/PEP_parte_1.pdf (08/06/2016).

Grindle, M. S. Good Enough Governance Revisited', Development Policy Review, 25(5), 553-574, 2007.

Grindle, M. S. Good Governance: The Inflation of an Idea, Faculty Research Working Paper Series RW, p.10-023: Harvard Kennedy School, 2010.

Grindle, M. S. Good Governance, R.I.P.: A Critique and an Alternative, Governance: An International Journal of Policy, Administration, and Institutions, 2016.

Hajer, M. A., \& Wagenaar, H. (eds.). Deliberative Policy Analysis Understanding Governance in the Network Society. Cambridge: Cambridge University Press, 2003.

Harrison, J., Smith, D., \& Kinton, C. Relational regions "in the making": institutionalizing new regional geographies of higher education', Regional Studies, 52(1), 1-15, 2017.

Healey, P. Transforming Governance: Challenges of Institutional Adaptation and a New Politics of Space, European Planning Studies, 14(3), 299-320, 2006. 
Hewitt de Alcántara, C. Uses and abuses of the concept of governance, International Social Science Journal, 50(155), 105-113, 1998.

Huther, J., \& Shah, A. Applying a Simple Measure of Good Governance to the Debate on Fiscal Decentralization, Policy Research Working Paper No. 1894. Washington, DC: World Bank, 1998.

Jessop, B. Territory, Politics, Governance and Multispatial Metagovernance, Territory, Politics, Governance, 4(1), 8-32, 2016.

Jones, M. Polymorphic Political Geographies, Territory, Politics, Governance, 4(1), 17, 2016.

Kaufman, D., \& Kraay, A. Growth without Governance. World Bank Policy Research Working Paper No. 2928. Washington, DC: World Bank, 2002.

Kooiman, J. Modern Governance. New Government, Society Interactions. London: Sage, 1993.

Levi-Faur, D. (ed.) The Oxford Handbook of Governance. New York: Oxford University Press, 2012.

Maskell, P., Bathelt, H., \& Malmberg, A. Building global knowledge pipelines: the role of temporary clusters, European Planning Studies, 14, 997-1013, 2006.

Mayntz, R. New challenges to governance theory, Jean Monet Chair Papers RSC $\mathrm{N}^{\circ}$ 98/50, 1998.

MCTelP. Argentina Innovadora 2020: Plan Nacional de Ciencia, Tecnología e Innovación. Lineamientos Estratégicos 2012-2015. Buenos Aires: Ministerio de Ciencia, Tecnología e Innovación Productiva, 2012.

Messner, D. The Network Society. Economic development and international competitiveness as problems of social governance. London: Frank Cass, 1997.

MI. Plan Estratégico Industrial 2020. Buenos Aires: Ministerio de Industria de la Nación Argentina (MI), 2011.

Ministerio de la Producción de Santa Fe. Cadena Algodonera Santafesina. Santa Fe: Ministerio de la Producción de Santa Fe, 2010.

Moltoni, L. Herramientas de diagnóstico de clusters y aportes para su reorganización (Segunda Parte), Economía y Desarrollo Agroindustrial (Vol. 2): Instituto de Ingeniería Rural. Instituto Nacional de Tecnología Agropecuaria (INTA), 2014 . 
MPFIPS. Argentina 2016. Política y Estrategia Nacional de Desarrollo y Ordenamiento Territorial Construyendo una Argentina equilibrada, integrada, sustentable y socialmente justa. Buenos Aires: Ministerio de Planificación Federal, Inversión Pública y Servicios (MPFIPS). Subsecretaría de Planificación Territorial de la Inversión Pública, 2004.

MPFIPS. Plan Estratégico Territorial / Avance II: Territorio e Infraestructura. Buenos Aires: Ministerio de Planificación Federal, Inversión Pública y Servicios (MPFIPS). Subsecretaría de Planificación Territorial de la Inversión Pública, 2011.

Naclerio, A., \& Trucco, P. Construir el Desarrollo con Políticas Públicas: Asociatividad, Tecnología e Innovación Productiva. El caso del Programa Sistemas Productivos Locales, Documentos y Aportes en Administración Pública y Gestión Estatal, 24(15), 33-65, 2015.

Ockstat, W. H. La implicación del Estado provincial en las dinámicas de gobernanza del desarrollo, Facultad de Ciencias Económicas. Santa Fe: Universidad Nacional del Litoral, 2015.

Orovitz Sanmartino, J. Crisis, acumulación y forma de Estado en la Argentina postneoliberal, Cuestiones de Sociología, 5-6, 235-253, 2009. Disponible en: http://www.memoria.fahce.unlp.edu.ar/art_revistas/pr.5115/pr.5115.pdf.

Oszlak, O. Open Government: Promises, Assumptions, Challenges, PATimes (Vol. 36, pp. 1-2): American Society for Public Administration, 2013.

Piore, M., \& Sabel, C. F. The second industrial divide. Possibilities for prosperity. New York: Basic Books, 1984.

Rose-Ackerman, S. What Does "Governance" Mean? Governance: An International Journal of Policy, Administration and Institutions. 2016

Scott, A. J. New industrial spaces. Flexible production organization and regional development in North America and Western Europe. London: Pion, 1988.

Schorr, M. (ed.). Argentina en la posconvertibilidad: ¿desarrollo o crecimiento industrial? Estudios de economía política. Buenos Aires: Miño y Dávila, 2013.

Signorelli, G. Reordenando el territorio: el cao de la regionalización en la provincia de Santa Fe, Argentina- 2008-2011, Quid 16, Número Especial, 145-161, 2013.

SSePyMEyDR. Reglamento Operativo Proyecto PNUD ARG/05/024 - Promoción de Clusters y Redes Productivas con Impacto en el Desarrollo Regional, 2005. Disponible en: www.sepyme.gov.ar/web: Ministerio de Industria y Turismo de la Nación Argentina. 
Storper, M. The regional world. Territorial development in a global economy. New York - London: The Guilford Press, 1997.

UnitedNations. Guidebook on promoting Good Governance in public-private partnerships. New York / Geneva: United Nations Economic Commission for Europe, 2008.

van Lindert, P., \& Verkoren, O. (2012). 'La planificación del desarrollo local bajo la descentralización y gobernanza local. Una reseña interpretativa de la literatura', Medio Ambiente y Urbanización, 76(1), 9-48.

Varesi, G. Á. La Argentina Postconvertivilidad: Modelo de Acumulación, Problemas del Desarrollo. Revista Latinoamericana de Economía, 41(161), 141-152, 2010.

Vigil, J. I. El Estado en Movimiento. Una revisión de la relación entre conceptos regionalistas y la política regional, Revista de Estudios Regionales, 103(MayoAgosto), 39-67, 2015.

Vigil, J. I., \& Priolo, D. J. Desafíos del Estado local: problemas en la articulación de políticas de múltiples geografías, Política - Revista de Ciencias Política, 52(1), 7-38, 2014.

WorldBank. Reforming Public Institutions and Strengthening Goverance: A World Bank Strategy. Washington, DC: World Bank, 2000.

José Vigil. Universidad Nacional del Litoral - Argentina. jvigil@fce.unl.edu.ar

Waldemar Ockstat. Universidad Nacional del Litoral - Argentina. waldemar.ockstat@gmail.com 